\title{
The Influence of Self-construal on Entrepreneurial Orientation and Growth of Micro-enterprises
}

\author{
Francis A. Oni* \\ National University of Lesotho \\ P.O. Roma 180 \\ Lesotho \\ Email: faodedara@yahoo.com \\ Mobile phone: (+266) 57649814 \\ Peter Khaola \\ National University of Lesotho \\ P.O. Roma 180 \\ Lesotho \\ Email:peterkhaola@gmail.com \\ Mobile phone: (+266) 58043421 \\ Patient Rambe \\ Central University of Technology, Free State \\ Private Bag X20539 \\ Bloemfontein, 9300 \\ South Africa
}

*Corresponding author 


\begin{abstract}
Literature acknowledges the critical role of self-construal in shaping entrepreneurial orientation and behaviour. While explanations for societal differences in entrepreneurial behaviours vary at organisational level, limited attention has been devoted to explaining the influence of self-construal on entrepreneurial orientation (EO) and growth of micro enterprises. This study examined the influence of self-construal of micro-enterprise owners on their EO (risk-taking and innovativeness) and the growth of their firms. Data collected using structured interviews administered on 80 micro-enterprise owners from Roma, Maseru, and Teya-Teyaneng in Lesotho were analysed using descriptive statistics, correlations, hierarchical regression analyses and partial least squares structural equation modeling (PLS-SEM). Findings show that the independent self-construal had positive and significant influence on the EO of micro-enterprises but the inter-dependent self-construal construct did not have a positive and significant effect on the EO. While independent self-construal negatively and significantly influenced enterprise growth, the interdependent self-construal did not have any influence on growth of micro-enterprises. The study recommends that universities and government departments such as Ministry of Small Business Development, Cooperatives and Marketing must provide entrepreneurial training to micro-enterprise owners on how to improve enterprise-oriented cultures and self-confidence in independent decision-making for the growth and survival of their enterprises.
\end{abstract}

Key words: Culture, Enterprise growth, Entrepreneurial orientation, Independent self-construal, Interdependent self-construal. 


\section{Introduction}

Self-construal, a term derived from perceived cultural differences in self, is an individual-level construct reflecting individualist and collectivist values (i.e. the extent to which people view themselves as separate or connected to others) (Siu \& Lo, 2011). Generally, there are two variants of self-construal namely: independent and interdependent self-construal (Markus \& Kitayama, 1991). There is a general consensus that individuals from any cultural background vary in their levels of independent and interdependent self-construal. Gardner et al. (1999) found that priming an independent or interdependent self-construal within specific cultures affects the social orientations of people belonging to those cultures. Therefore, people with independent self-construal tend to focus on their needs, selffulfillment, goals, thoughts and feelings, while those with interdependent self-construal emphasize developing relationships, and act in accordance with anticipated expectations of social norms and others (Siu \& Lo, 2011; Zampetakis et al., 2017). By connecting both individual and social-contingent aspects of the cultural self, selfconstrual ideally resonates with the Theory of Planned Behaviour (TPB) components which emphasize the contribution of subjective behavior to entrepreneurship orientation. Studies that examined antecedents of TPB to entrepreneurial intentions in different cultures provide evidence on the capacity of independent and interdependent self-construal to shape entrepreneurial cognitions (Zampetakis et al., 2017; Zhang et al., 2017). These researchers contend that while higher levels of TPB components (i.e. attitudes, subjective norms, and perceived behavioral control) may influence entrepreneurial orientations positively or negatively, individuals from cultural orientations, that is, those exhibiting independent and interdependent self-construal, may react differently to business creation. Therefore, individuals possessing different forms of self-construal are differently positioned to exploiting entrepreneurial opportunities inherent in their business environment.

National culture is also conceived as a critical determinant of the performance of individual organisations and business sectors (Aluko, 2003; Ostapenko, 2015; Yu et al., 2019). These researchers content that cultural variables displayed a low level of labour turnover, high level of commitment to work, positive work value, beliefs, attitudes and norms in the selected firms studied. Therefore, it can be contended that 
comprehending culture holistically enables researchers to interpret the influence of cultural phenomena on individual culture's behaviour (self-construal) and explain people's behavioural actions (Lewis, 2006). Also, it can be argued that individuals belonging to collectivist cultures may be predisposed to displaying interdependent selfconstrual while those from individualist and competitive oriented cultures may be more inclined to exhibit independent self-construal. There is the consensus that culture scholars conceive national cultural differences to play a fundamental role in shaping individual values and world views (Baluku et al., 2019; Kafetsios, 2019; Hofstede, 1980). Nevertheless, since venture creation is founded on the profit motive which sustains individual worth and social standing (i.e. supporting a sense of individualism), it is inconceivable not to associate it with the quest for individualism and competition even in those cultures which may be deemed as pluralist and collectivist (Lee et al., 2019; Fernandez-Serrano et al., 2018; Kececi, 2017). Consistent with this logic, it may not be obvious that coming from a specific culture automatically orients one to exhibit specific dimensions of self-construal as that may amount to compartmentalizing individuals from the same culture (assuming cultural homogeneity) (Shirokoya et al., 2018). The risk of presupposing cultural homogeneity is even pronounced in microenterprises where firm rivalry and quest for differentiation as a signifier of competitive advantage naturally compels such entrepreneurs to pursue uniqueness and not homogeneity. Therefore, while the culture of the owner/manager provides values, rules, traditions, behaviours and goals which may be fundamental to entrepreneurial exploits, it is unclear how culture shapes EO due to the murkiness of the entrepreneurial environment (Lee et al., 2019).

Notwithstanding the pioneering study by Hofstede (1980), the extent to which national culture (especially sub-cultures such as self-construal) impacts EO and the growth has not received sufficient attention (Zampetakis et al., 2017; Siu \& Lo, 2011). Despite the proliferation of studies on the impact of national culture on EO in organisations (Driskill, 2018; Lee et al., 2019; Wales et al., 2019), few studies have focused on the impact of sub- culture dimensions such as individual cultures (self-construal) on microentrepreneurs compared to organizational or national culture (Siu \& Lo, 2011; Zampetakis et al., 2017). The de-emphasis on self-construal is surprising because 
culture values revolve around individuals within organisations or countries (Siu \& Lo, 2011).

In the two studies on the role of independent and interdependent self-construal carried out on university students based on the Theory of Planned Behaviour (TPB) perspective, the results from first study using structural equation modeling analyses found that chronic independent self-construal is related to attitudes towards entrepreneurship and moderated relationships between attitudes and entrepreneurial intentions (Zampetakis et al., 2015). The authors contend that participants primed with an independent self-construal in the second study had more favourable entrepreneurial attitudes, but not entrepreneurial orientations than participants primed with an interdependent focus. This demonstrates that the individualist self-construal perspective seems to cohere with the "lone wolf" perspective inherent in entrepreneurship compared to the inter-dependent dimensions of self-construal. Similarly, literature established that the type of self-construal a person has affects his or her emotions, cognitions, motivations, and orientations (Walker et al., 2005) and entrepreneurial orientations could be one of such. Likewise, a research based on 147 undergraduate students highlights the significance of self-construal, emotions and cultural orientation in the entrepreneurial process (Zampetakis et al., 2017).

Even though several strands of research have been woven into our knowledge of how self-construal influences entrepreneurship as shown above, there are limitations associated with some past studies. First, many studies make use of a country as a proxy variable of culture based on Hofstede's (1980) classical scores of individualism and collectivism. This approach is problematic because it ignores "within country" differences in cultural values among individuals and subcultures (Siu \& Lo, 2011). This is particularly the case in Lesotho where there are wide variations between individual cultures due to diverse education backgrounds and socio-economic status of citizens. In other words, an average score of culture in a particular country does not necessarily represent an individual's cultural values in such a country (Zampetakis et al., 2017). There is therefore a need to assess the cultural values held by individuals to ensure that cultural orientation is appropriately calibrated as it relates to individual's EO. Secondly, many past studies covering culture and self - construal as it relates to 
entrepreneurship (Wang, 2012; Zampetakis, et al., 2017) are based on entrepreneurial intentions (EI), and not actual entrepreneurial behaviours. The findings of past studies on student samples and not on actual entrepreneurship behaviours of micro-enterprise managers/ owners eludes our understanding of how these antecedent variables are implicated in entrepreneurship (Bunagan \& Sison, 2019). Both approaches are problematic because El may not be realized, and student samples are not all exposed to real work dynamics confronted by micro-enterprise owners (Lekhanya, 2016; Afande, 2015).

The aim of the study is, therefore, to examine if self-construal (individualismcollectivism cultural orientation) of micro-enterprise owners influences their EO dimensions (in particular risk-taking and innovativeness) and the growth of their businesses. The research question guiding this study is: how does self-construal influence EO and growth of micro-enterprises? The pursuit of the aforementioned aim with reference to Lesotho is informed by paucity of literature on the influence of selfconstrual on EO (risk-taking and innovativeness) of Basotho entrepreneurs and the growth of their businesses. To our knowledge, there has not been any study carried out on how sub-cultures influence the success of micro-enterprises in Lesotho. The uniqueness of the Basotho sub-culture lies in the interdependent nature of the Basotho communities despite the threats of globalization to superimpose individualist values. This postulation finds support in the literature that conceives people from developed countries such as United States of America as exhibiting independent self-construal (and therefore value being unique, expressing one's inner attributes, etc.) while individuals in or from developing countries (Asia, Africa, and Southern Europe) are more likely to have interdependent self-construal (and therefore value belonging, maintaining harmony, etc.) (Walker et al., 2005; Markus \& Kitayama, 1991). Overall, we are cautious of this oversimplification of reality on the consistent use of this term in both advanced and developing countries as forces of urbanization, globalization and modernity and moral re/degeneration seems to be affecting both developed and developing nations and hence the need to test these assumptions in a perceivably collectivist culture. Suffice to state that the type of self-construal a person has affects his or her emotions, cognitions, motivations and orientations. If that obtains, individuals from perceivably collectivist cultures are bound to encounter challenges with applying 
entrepreneurship behaviours as running businesses require the exertion of independent orientation (Lee et al., 2019). This contradiction between collectivist selfconstrual and entrepreneurial pursuits may explain the low level of entrepreneurial activities in Lesotho. Moreover, the expectation for business cooperation may conflict with demands for individual thrift and entrepreneurship success in cooperative societies in the Kingdom.

\section{The relevance of examining EO and micro-enterprise growth with reference to Lesotho}

It is widely accepted that business creation and entrepreneurship provide the most sustainable and reliable way to get out of chronic unemployment and economic stagnation (Boskov, 2016; OECD, 2017; Obi et al., 2018). A strong entrepreneurship drive is particularly relevant for Lesotho where 28\% (World Bank Report, 2019) of the youth remain unemployed and often migrate to South Africa for greener pastures. Recent UNDP report ranks Lesotho as one of the poorest countries in the world by all standards ranging from multi-dimensional poverty, GDP per capital and consumption levels (UNDP, 2018). Yet there is also a growing body of literature that presents entrepreneurship as a possible panacea to the challenges of poverty, inequality and unemployment in the world (Ogunlusi et al., 2018; Fairlie et al., 2019).

Research on drivers of entrepreneurship and business creation therefore remains important in all countries, especially in developing countries with relatively high levels of unemployment. Since the growth of enterprises is considered fundamental to income generation, wealth creation, breaking structural inequalities in society (Tekola \& Gidey, 2019); examining such growth in relation to sub-cultures of individual entrepreneurs would be fundamental to the growth of small ventures.

According to a comprehensive study on the state of Small Enterprise in Lesotho, it is estimated that small businesses comprise at least 85 percent of Lesotho's private sector (Ministry of Trade, Industry, Cooperatives and Marketing, (MTICM), 2008). However, most of the micro-enterprises in Lesotho are survivalists, and have limited potential for growth and expansion (MTICM, 2008). One could argue that the lack of knowledge of the self-construal mode contributes to preventing Lesotho's entrepreneurship support programmes from designing interventions that are integral to promoting the growth of micro-enterprises in the country. This is in addition to the 
broad range of constraints which hinder enterprise growth acknowledged in Basotho literature such as lack of product demand, trust, access to markets, competition, high operational costs, limited range of suppliers, access to finance, and high taxes (MTICM, 2015). Since self-construal also explains entrepreneurial challenges from the perspective of one's capacity to influence outcomes or to attribute them to external circumstances beyond the control of the entrepreneurs, exploration of self-construal as an antecedent of EO and enterprise growth could be fundamental to judging whether the aforementioned external constraints are not motivated by the self-serving bias (the tendency to attribute problems to external factors, and successes to personal factors). For instance, all cited challenges above refer to external factors beyond the control of the micro-enterprises owner, and very little can be attributed to individual factors such as cultural orientation, individual values, knowledge, and skills which are observed elements of independent or interdependent self-construal (Zampetakis, 2017).

\section{Theoretical Approach}

One area of entrepreneurship literature where a cumulative body of knowledge has emerged is that of EO (Wales et al., 2015; Wales, 2018). EO is defined as the processes, practices, and decision-making styles of organisations that act entrepreneurially (Lumpkin \& Dess, 1996). Anderson et al. (2015) give a concise but encompassing and archetypal definition of EO as a firm's decision-making practices, managerial philosophies, and strategic behaviors that are entrepreneurial in nature. The three dimensions of EO which have traditionally captured EO as a firm-level predominant strategic posture are innovativeness, proactiveness, and risk-taking derived from Danny Miller's early work on firm's strategy-making (Miller, 2011). These dimensions have been extended to five to include autonomy and competition (Wach, 2015). This study focuses on innovativeness and risk-taking dimensions of EO. These dimensions are the most popular in measuring EO. EO remains a vibrant research topic as it continues to attract spirited discussion and attention of scholars (Martens et al., 2016; Wales, 2015; Covin \& Wales, 2019).

Three major theoretical approaches shape this study: the Theory of the "Entrepreneurial Event" developed by Shapero \& Sokol in 1982, the Theory of Planned Behaviour (TPB) launched by Ajzen in 1991, and Construal Level theory. According 
to the TPB, intent or readiness to act is the most proximal determinant of behaviour. In this model, an individual's behavioural intention is influenced by behavioural, normative, and control beliefs (Ajzen, 1991; Ajzen \& Fishbein, 2005; Ajzen, 2019). Behavioural beliefs refer to attitudes about the targeted topic regarding likelihood that specific behaviours would occur while normative beliefs involve the extent to which it is perceived that others expect certain behaviour, coupled with one's personal motivation to comply, perceived behavioural control refers to one's assessed ability to overcome obstacles and accomplish the behaviour (Ajzen, 2019).

EO is seen as a common construct utilized to measure attitude towards entrepreneurship (Kollmann et al., 2007), and attitude can be used to predict intention and/ or behaviour. A good fit was found for a modified Theory of Planned Behaviour (TPB) model with self-construal dimensions (Maslowsky et al., 2015). Interdependent self-construal was linked to subjective norms, while independent selfconstrual was linked to perceived behavioural control, which can both predict EO (Mancha \& Yoder; 2015; Criado-Gomis et al., 2018 ).

Making decisions for the self (independent self-construal) and deciding for or providing advice to others (interdependent self-construal) differs in weight that people attach to desirability and feasibility (Păunescu et al., 2018). Based on Construal Level Theory (CLT), in a decision-making process, individuals who decide for others tend to focus more on social desirability than on feasibility compared with those who decide for themselves (Chen \& Li, 2018; Zhang et al., 2017). Arguments on social desirability are consistent with perceptions of inter-dependent self-construal when what is considered desirable for society is good for everyone, while the independent self-construal would be aligned to the feasibility where focus is on an individual entrepreneur's capacity to realize entrepreneurial orientations. Based on our personal knowledge, one can say that the perceptions of social desirability and perceptions of feasibility will have impact on firm growth.

The rest of this paper is organized as follows: first, the paper reviews relevant literature and the development of hypotheses. This is followed by research methodology and the research findings, and the last section provides the discussion, implications of the study, conclusions and recommendations of the paper. 


\section{Review of relevant literature and development of hypotheses}

Researchers generally agree that EO is a key concept in developing strategies in the expectations of doing something new and exploiting opportunities (e.g. new business) that other organizations cannot exploit and will enable individual to undertake business processes, practices, and engage in decision-making styles that will enable the individual to act entrepreneurially and give business a sustainable competitive advantage (Jalali et al., 2014; Emmanuel, 2017). Therefore, EO remains an essential concept in the formation of a new business (Anderson et al., 2015; Duru et al., 2018). EO refers to the processes, practices and decision-making activities that lead to new entry (Lumpkin \& Dess, 1996). The authors contend that it involves the aims and actions of key players functioning in a dynamic generative process that is aimed at new venture creation. EO is an attribute at a firm-level identifiable through the display of persistent entrepreneurial behavioural patterns. EO is undoubtedly a multidimensional construct comprising of proactiveness, innovativeness, risk-taking, competitive aggressiveness, and autonomy (Wach, 2015).

Even though a growing number of studies suggest how self-construal affects entrepreneurial intentions (Siu \& Lo, 2011; Bagheri \& Pihie, 2014; Hallam et al., 2016), we are not aware of studies that examine how self-construal influences EO directly. Since EO can be seen as a common construct that measures attitude towards entrepreneurship (Kollmann et al., 2007), and attitudes can be used to predict intention and/or behaviour, we argue then that the self-construal should conceptually influence the dimensions of EO and in turn, should influence the growth of micro-enterprises. In view of the reality that most studies discussing the impact of self-construal on EO dimensions have been in advanced countries (Anlesinya et al., 2015), this study seeks to examine if these studies have some resonance with emerging country context such as that of Lesotho which is culturally characterised by interdependency like any other African countries (Walker et al., 2005; Jones et al., 2018) as opposed to independent orientation that businesses require (Farrington \& Matchaba-Hove, 2011).

\section{Self-construal and risk-taking}

Risk-taking is intrinsic to entrepreneurship. If one is not prepared to take risks in venturing into the unknown (personal, social, and psychological in nature), "committing a relatively large portion of assets," and sometimes "borrowing heavily" (Hasche \& 
Linton, 2018: 99), it is inconceivable to engage in entrepreneurship as entrepreneurial pursuits always involve risks. Risk can also be related to risk-return and trade-off, or the probability of a loss (Lechner \& Gudmundsson, 2014), or tolerance of uncertainty (Gunawan et al., 2015). The risk to experiment with new ideas is key to business creation. As it is popularly believed that "nothing ventured, nothing gained", risks must be taken in order to achieve something substantial or meaningful. Therefore, risk taking is the "differentiator" because most people are unwilling to take risks (Hasche \& Linton, 2018; Covin \& Wales, 2018; Wales et al., 2013). The risk-takers globally and unsurprisingly stand out, and are the only ones with chances of recording success. Taking risk depends on the nature of individual whether as a risk averter, a risk taker or risk neutral.

One of the characteristics that entrepreneur should have according to trait theory is the ability to take risk (Block et al., 2015). Dess and Lumpkin (2005) share the same view when they state that risk-taking involves making decisions in the face of uncertainty. People in individualistic cultures rely more on their abilities than on the view of others when making critical decisions (Siu \& Lo, 2011). It therefore stands to reason that independent self-construal could have more impact on risk-taking than inter-dependent self-construal, especially among peoples with individualistic culture. In support of this notion, studies show that individual attitudes and self-efficacy have stronger impact on entrepreneurial orientations in individualistic countries than social norm (extent to which orientations are influenced by significant others) (Autio et al., 2001; Krueger et. al., 2000). Since business creation is often related to risk-taking (Dess \& Lumpkin, 2005) and independent self-construal is related to attitudes and intentions to create a business (Zampetakis et al., 2017), independent self-construal is expected to influence the EO dimension of risk-taking. This situation can therefore be hypothesized as follows:

H1a: There is a positive relationship between independent self-construal and risktaking.

H1b: The relationship between independent self-construal and risk-taking is stronger than the relationship between interdependent self-construal and risk-taking. 
Self-construal and innovativeness

For micro-enterprises, innovativeness is essential for long-term survival of the firm (Zellweger \& Sieger, 2012). Innovativeness refers to openness to new ideas (Frisharmmar \& Horte, 2007), pursuit of creative and novel solutions (Knight, 2001), or process and product creativity (Dess \& Lumpkin, 2005). As dimensions of EO, innovativeness and risk-taking are closely related (Wach, 2015). This is not surprising because innovative people take calculated risks (Block et al., 2015). Since risk-taking and openness to experience (innovativeness) are traits related to oneself (Kerr et al., 2018; Prasad et al., 2018; Cuesta et al., 2018; Kerr et al., 2019), and not the group, it is plausible that independent self-construal (and not interdependent self-construal) should be related to innovativeness. Based on this premise, the following can be hypothesized:

H2a: There is a positive relationship between independent self-construal and innovativeness.

H2b: The relationship between independent self-construal and innovativeness is stronger than the relationship between interdependent self-construal and innovativeness.

\section{Self-construal and entrepreneurial orientation}

Since EO reflects risk-taking and innovativeness, and both dimensions of EO should conceptually be influenced by self-construal as argued above, then, self-construal should plausibly influence EO. In the context of a closely related term, namely entrepreneurial intention (EI), studies find that self-construal either directly influences El, or interacts with predictors of El to influence the latter (Siu \& Lo, 2012; Zampetakis et al., 2017). It is therefore plausible to hypothesize as follows:

H3a: There is a positive relationship between independent self-construal and EO.

H3b: The positive relationship between independent self-construal and EO is stronger than the relationship between interdependent self-construal and EO. 


\section{EO and Micro-enterprise growth}

Firm growth has generated a lot of interest among social scientists and practitioners alike (Rajapathirana \& Hui, 2018; Okangi, 2019). Growth is seen as the direct outcome of risk-taking, proactive and innovative behaviour of an entrepreneur as researchers explicate that EO is one of the most generally used concepts in strategy literature for enhancing firm growth, competitiveness, success, profitability and performance (Rezaei and Ortt, 2018; Neneh et al., 2016). In other words, growth is seen as the outcome of EO. EO is centered on the behaviour that can be used as a gizmo for enhancing micro-enterprises growth (Neneh et al., 2016). Empirical studies on entrepreneurship demonstrate that there is a positive relationship between EO and firm performance leading to growth (Neneh et al., 2016; Dissanayake \& Semasinghe, 2016; Okangi, 2019). Several empirical studies support this view. For instance, Kraus et al. (2012) found a positive relationship between EO and growth in Netherlands. Similar results were found by Aziz et al. (2014) in Malaysia, Neneh et al. (2016) in South Africa, Păunescu et al. (2018) in Romania, and Okangi (2019) in Tanzania. However, a handful of research findings have revealed insignificant and sometimes negative correlations between $\mathrm{EO}$ and firm performance with the reason that relationship between EO and firm performance is mediated by learning orientation whereby flexibility and application of required skills in doing things are encouraged within the firm (Wambugu et al., 2015; Arbaugh et al., 2010). Similarly, studies indicate that not all of the dimensions of EO directly or positively influence business growth when the industry's contextual factors are considered (Lumpkin \& Dess, 1996). These mixed results partly motivate this study as it remains fuzzy the nature of the relationship between these variables. However, Covin and Slevin (1991) postulate that entrepreneurial firms with innovative, proactive and risk-taking strategic orientation would attain growth. Based on the above findings, the following can be hypothesized:

H4: There is a positive relationship between EO and SME growth.

\section{Methodology}

A descriptive research design was applied to examine the influence of self-construal on $\mathrm{EO}$ and growth of micro-entrepreneurs in Lesotho. 


\section{Sampling and procedures}

Data were collected from primary sources using structured interviews directed to the owners of micro-enterprises. The research population consisted of small business owners operating in Roma, Teya-Teyaneng, Hamokhalinyane, and the central business unit (CBD), Maseru District, Lesotho. A sample size of 80 was selected from the list of small business owners obtained from the Ministry of Trade using convenience non-probability sampling method. Because one-to-one interviews were used, the response rate was $100 \%$.

\section{Assessment of variables}

To ensure the validity and reliability of data collected, existing scales were used to assess the variables of the study.

Self-Construal: The culture value scale (CVSCALE) adapted from Yoo, Donthu and Lenartowicz (2011) was used to assess individualism / collectivism (independent/interdependent) culture values. On a scale ranging from $1=$ strongly disagree to $5=$ strongly agree, micro-enterprise owners were asked to rate the extent to which they agree with certain statements. Three items used to measure independent self-construal were: "it is important that I do my work better than others"; "my personal identity and being independent of others is important to me", and "winning is everything to me". Three items used to measure interdependent selfconstrual were: "an individual should sacrifice self-interest for the group", "group welfare is more important than individual rewards", and "group loyalty should be encouraged even if individual's goals suffer". The Cronbach's alphas $(\alpha)$ of the scales were 0.93 and 0.88 respectively.

To verify that the scale measured what it intended to measure, namely culture values, we included uncertainty avoidance and long-term planning as additional values of culture were included. Conceptually, all four should be moderately correlated, but distinct constructs.

Risk-taking: Two items adapted from Schwartzer and Jerusalem's (1995) scale were used to assess this construct. The items were: "I am confident that I could deal efficiently with unexpected events" and "thanks to my resourcefulness, I know how to handle unforeseen events". The Cronbach's alpha $(\alpha)$ of the scale was 0.96 . 
Innovativeness: Three items from Jackson's (1976) scale (JPI) were used to measure this construct. The items used were "I love to think up of new ways of doing things", "I have vivid imagination", and "I have excellent ideas". The Cronbach's alpha of the scale was 0.95 .

For risk-taking and innovativeness, the scale ranged from $1=$ very false to $5=$ very true.

EO: This construct was measured with 5 items from risk-taking and innovativeness as explained above. The Cronbach's alpha $(\alpha)$ was $=0.96$.

Enterprise growth: Number of employees was used as a proxy for enterprise growth.

\section{Data analysis}

Statistical Package for Social Sciences (SPSS, v. 20) and Smart PLS 3 were used to analyse the data for this study. Specifically, statistics for correlations, model measurement, and structural model were used to address the hypotheses.

Compared to covariance-based structural equation modelling (CB-SEM), partial least squares structural equation modelling (PLS-SEM) is considered appropriate where the focus of research is on prediction and explanation of key constructs; the sample size is small; the model is made of reflective and formative constructs; available data is non-normal; and the model consists of single-item latent variables (Hair et al., 2019; Hair et al., 2011). Data analysis in our model was more suited to PLS-SEM than CBSEM because the focus of our study wason prediction and explanation of key variables, the sample size was small, and our final exogenous latent variable (performance) consisted of one item (number of employees).

Construct validity of the measurement model was evaluated by assessing the convergent and discriminant validity of the model (Hair et al., 2011).

Traditionally, convergent validity is confirmed when all standardised loadings (outer loadings in SmartPLS) are statistically significant and 0.7 (or higher), the average variance extracted (AVE, average amount of variation that a latent variable explains in the observed variable) of each variable is 0.50 or higher, and composite reliability of each variable is 0.70 or higher (Hair et al., 2011; Nel \& Boshoff, 2019). 
To assess discriminant validity, we used Fornell-Larcker criterion. According to this criterion, the square-root of the AVE of each variable should be greater than the correlations of that variable with other variables in the model (Hair et al., 2011; Nel \& Boshoff, 2019).

\section{Results}

Assessment of the measurement model

The results of the measurement models are shown in Table 1.

\section{Insert Table 1}

As shown in Table 1, outer loadings on all constructs were 0.7 (or higher) and significant, and AVE of each latent construct was higher than 0.50 . Similarly each construct had the composite reliability that was higher than 0.70 (Hair et al., 2011). These figures provide evidence of convergent validity of the constructs under study.

To assess discriminant validity, we used Fornell-Larcker criterion. The results are summarised in Table 2.

\section{Insert Table 2}

As shown in Table 2, the square-root of the AVE of each construct (figures in the diagonal) was higher corresponding figures in each column and row, intimating that the measurement model had adequate discriminant validity.

To have a general idea of the relationship among study variables, we conducted zeroorder correlations. The detailed results are shown in Table 3.

\section{Insert Table 3}

As shown in Table 3, while independent self-construal (individualism) correlated positively and significantly with risk-taking $(r=0.60, p \leq 0.01)$, innovativeness $(r=0.60$, $p \leq 0.01)$, and EO ( $r=0.62, p \leq 0.01)$, interdependent self-construal (collectivism) correlated positively, but only marginally with $E O(r=0.22, p \leq 0.05)$. These figures 
generally suggest that the higher the independent self-construal (individualism), the higher the EO (and its components) and vice versa. Hypotheses 1a, 2a and 3a were hence supported.

Whereas independent self-construal did not correlate significantly with enterprise growth $(r=0.12, p \geq 0.05)$, the interdependent self-construal correlated negatively and significantly with enterprise growth $(r=-0.31, p \leq 0.01)$. In other words, the higher the interdependent self-construal of the owner manager, the lower the enterprise growth in terms of the number of employees employed.

Though not hypothesized in this study, while age correlated negatively with EO ( $r=-$ $0.39, p \leq 0.01)$, level of education correlated positively with $E O(r=0.57, p \leq 0.01)$, suggesting that younger people with higher levels of education were more likely to possess higher EO. Interestingly, notwithstanding their lower EO, older microenterprise owners were more likely to have enterprises with more employees than their younger counterparts $(r=0.25, p \leq 0.05)$. Finally, micro-enterprise owners with prior business experience were more likely to have enterprises with more employees on average (Mean $=1.5$, about 2 employees) than micro-enterprise owners who started businesses without such experience $(M=0.69$, about 1 employee), $\quad(t(78)=$ -2.95, $\mathrm{p} \leq$ 0.05). Even though the sample was arguably small, we conducted regression analyses to examine the unique effects of the independent variables on EO and enterprise growth. We included other dimensions of culture as control variables (e.g. uncertainty and long-term planning). The results are shown in Table 4 below.

\section{Insert Table 4}

Table 4 suggests that after controlling for the effects of other variables, independent self-construal had significant and positive influence on EO $(\beta=0.36, p \leq 0.01)$. This reconfirms the utility of the independent self-construal on EO. Though not hypothesized in this study, the influence of education level $(\beta=0.41, p \leq 0.01)$ and prior business experience $(\beta=0.24, p \leq 0.01)$ on EO was again confirmed after controlling for other variables.

In terms of enterprise growth, the regression results suggested that the effects of interdependent self-construal on enterprise growth were adverse $(\beta=-0.33, p \leq 0.01)$. 
In line with hypothesis 4 , EO had positive effects on growth $(\beta=0.30, p \leq 0.01)$. While both age $(\beta=0.38, p \leq 0.01)$ and $E O(\beta=0.30, p \leq 0.01)$ continued to show positive effects in the regression model, prior business experience only showed marginal influence $(\beta=0.21, p \leq 0.05)$, and education level $(\beta=0.05, p \geq 0.05)$ did not show any unique effects on enterprise growth once other variables were controlled for.

In sum, the results suggest that micro-enterprise owners were likely to have high EO if they held independent values; had higher education level; and had business experience before they started their businesses. Enterprise growth was likely to be influenced positively by age and EO of the micro-enterprises owner.

\section{Structural Model}

Due to the small sample size, we deployed PLS-SEM to further examine the hypothesised relationships. The relationships between variables are shown in Table 5 and illustrated in figure 1.

\section{Insert Table 5}

As was the case in first generated regression results above, the results of the PLSSEM (second generated regression) showed insignificant relationship between interdependent self-construal and EO, and negative relationship between interdependent self-construal and growth. Similarly, there were significant relationships between independent self-construal and EO, insignificant relationship between independent self-construal and growth, and significant relationship between EO and growth (as shown in Table 5 or Figure 1).

\section{Insert Figure 1}

\section{Discussion}

The aim of this study is to examine if self-construal of selected micro-enterprise owners in Lesotho influence their EO and the growth of their enterprises.

The results show that micro-enterprise owners with high independent self-construal scored high on risk-taking, innovativeness, and EO. This is consistent with several studies that show that independent self-construal influences entrepreneurial emotions and attitudes (Zampetakis et al., 2017); EO (Jalaliet al., 2014; Mancha \& Yoder, 2015; Oliveira Jr. et al., 2016; Criado-Gomis, 2018; Lee et al., 2019); and entrepreneurial 
behaviour (Covin \& Lumpkin, 2011; Cuesta et al., 2018). More specifically, Zampetakis et al. (2017) found that the individual's self-construal relates positively to attitudes towards entrepreneurship, and moderates the attitude-entrepreneurial orientation link. Similarly Siu and Lo (2011) found that the interdependent selfconstrual moderates the relationship between perceived social norm towards entrepreneurship and EO in collectivist country (China).

Against expectations, our results show that interdependent self-construal did not have any influence on risk-taking, innovativeness and EO. Interestingly, of the two forms of self-construal, only interdependent self-construal had significant influence on growth. This implies that people with high interdependent self-construal are likely to run microenterprises with significantly lower number of employees. While the importance of selfconstrual may be culture-bound (Siu \& Lo, 2011). Our results support studies that intimate that independent self-construal is good for entrepreneurship (Kerr et al., 2018; Kerr et al., 2019).

Some important results are worth mentioning pertain to the effects of education on EO; the effects of prior business experience on both EO and enterprise growth, and the effects of $\mathrm{EO}$ on enterprise growth.

Our results suggest that education has a significant influence on EO, specifically suggesting that those with higher education are more likely to have higher EO than those with lower levels of education. This is important because it shows that not all micro-enterprises who started businesses are entrepreneurial, and that education matters in entrepreneurship (Bakotić \& Kružić, 2010; Din et al., 2016; Egerová et al., 2017). In line with prior studies that show that prior business experience is important in enterprise creation (Gibb, 2009; Staniewski, 2016), the current study found that people who had been in business before establishing their current enterprises are likely to have higher EO and more employees (enterprise growth). Siu and Lo (2011) found that the relationship between previous entrepreneurial experience and EO was mediated by entrepreneurial self-efficacy. It is possible that exposure to business helped the respondents to know the problems of customers and how to solve them. EO is positively and significantly related to the number of employees in an organisation (growth). This confirms the findings of previous studies that micro-enterprise owners who are innovative and can take risks are better able to grow their businesses than those who are less innovative and who are risk averse (Frisharmmar \& Horte, 2007; Zellweger \& Sieger, 2012; Block et al., 2015). 


\section{Implications}

\section{Managerial}

Based on the results of this study, policy makers are strongly encouraged to engender values of independence (independent self-construal) and self-confidence among micro-enterprise owners to improve their EO. This can be done through training workshops and awareness programmes of budding and existing entrepreneurs. As shown by our results, prior business experience is important for improving EO and success of micro-enterprises. In this regard, it would be beneficial for policy makers and financiers to align financial and non-financial support with business experience of those who want to start their businesses. Similarly, financing and supporting microenterprise owners with EO would help many micro-enterprises to graduate from survival stage to formal enterprises that can contribute to job creation and tax of African countries.

\section{Theoretical}

Our study extends prior studies in two significant ways. First, it is based on actual SMEs and not student samples. Second, it does not only examine the effects of selfconstrual on attitudes, personality and intentions, but also model its impact on actual business performance.

\section{Conclusion}

The present study aims to examine if self-construal of selected micro-enterprise owners in Lesotho influences their EO and the growth of their enterprises. The results show that micro-enterprise owners with high independent self-construal scored high on risk-taking, innovativeness, and EO. Even though interdependent self-construal did not have any significant influence on risk-taking, innovativeness and EO, it adversely affected enterprise growth. In summary, this study shows that self-construal is a viable concept worth studying in the micro-enterprise sector. Future studies may consider testing the aggregated influence of the common five dimensions of EO in a single study. 


\section{References}

Afande, O. F. (2015). Factors influencing growth of small and microenterprises in Nairobi central business district. Journal of Poverty, Investment and Development, 9 (1): $104-130$.

Aluko, M. A. O. (2003). The impact of culture on organizational performance in selected textile firms in Nigeria. Nordic Journal of African Studies 12(2): 164-179

Anderson, B.S., Kreiser, P.M., Kuratko, D.F., Hornsby, J.S. and Eshima, Y., (2015). Reconceptualizing entrepreneurial orientation. Strategic Management Journal, 36 (10): 1579-1596.

Anlesinya, A., Eshun, P. and Bonuedi, A.F., (2015). Entrepreneurial orientation dimensions and profitability nexus: evidence from micro enterprises in the retail sector in a developing country. International Journal of Small Business and Entrepreneurship Research, 3(7) : 79-87

Ajzen, I., (2019). Consumer attitudes and behavior: The theory of planned behavior applied to food consumption decisions. Rivista di EconomiaAgraria, 70 (2): 121138.

Arbaugh, J.B., Desai, A., Rau, B. and Sridhar, B.S., (2010). A review of research on online and blended learning in the management disciplines: 19942009. Organization Management Journal, 7(1): 39-55.

Autio, E., Keeley, R. H., Klofsten, M., Parker, G. G. C. \& Hay, M. (2001). Entrepreneurial intent among students in Scandinavia and in the USA. Enterprise Innovative Management Studies, 2:145-160.

Aziz, R. A., Mahmood, R., Tajudin, A., \& Abdullah, M. H. (2014). The Relationship between Entrepreneurial Orientation and Business Performance of SMEs in Malaysia. International Journal of Management Excellence, 2(3): 221 - 226.

Bakotić, D.; Kružić, D. (2010): Students' perceptions and intentions towards entrepreneurship: the empirical findings from Croatia, The Business Review, Cambridge, 14(2): 209-215.

Baluku, M.M., Kikooma, J.F., Bantu, E., Onderi, P. and Otto, K., (2019). Impact of personal cultural orientations and cultural intelligence on subjective success in self-employment in multi-ethnic societies. Journal of Global Entrepreneurship Research, $9(1)$, p.8. 
Block, J., Sandner, P. and Spiegel, F. (2015). How do risk attitudes differ within the group ofentrepreneurs? The role of motivation and procedural utility. Journal of Small Business Management, 53(1):183-206.

Boskov, T., (2016). Growing the Global Economy through SMEs International Aspirations. LAPLAMBERT Academic Publishing.

Bunagan, V.D. and Sison, M.S.M., (2019). Entrepreneurial Culture and Orientations of SMEOwners/Managers in the Kingdom of Bahrain. Journal of Small Business andEntrepreneurship, 7(1) 60-70.

Chen, H. and Li, S., (2018). Measuring the psychological distance between an organization and its members-the construction and validation of a new scale. Frontiers in psychology, :8.2296.

Covin, J.G. and Miller, D., (2014). International entrepreneurial orientation: Conceptual considerations, research themes, measurement issues, and future research directions. Entrepreneurship Theory and Practice, 38(1): 11-44.

Covin, J. G. and Wales, W. J. (2018). Crafting High-Impact Entrepreneurial Orientation Research:Some Suggested Guidelines. Entrepreneurship Theory and Practice. EntrepreneurshipTheory and Practice 43(1): 3-18.

Covin J, and Slevin D (1991) Strategic management of small firms in hostile and benign environments. Strategic Management Journal, 10:75-87.

Covin, J.G. and Wales, W.J., (2019). Crafting high-impact entrepreneurial orientation research: Some suggested guidelines. 3-18.

Criado-Gomis, A., Iniesta-Bonillo, M.Á. and Cervera-Taulet, A., (2018). Sustainable entrepreneurial orientation within an intrapreneurial context: effects on business performance. International Entrepreneurship and Management Journal, 14(2): 295-308.

Cuesta, M., Suárez-Álvarez, J., Lozano, L.M., García-Cueto, E. and Muñiz, J., (2018). Assessmentof eight entrepreneurial personality dimensions: Validity evidence of the BEPE battery. Frontiers in Psychology, 9.

Dess, G. G. \& Lumpkin, G. T. (2005). The Role of Entrepreneurial Orientation in Stimulating Effective Corporate Entrepreneurship. Academy of Management Perspectives, 19(1). 147-156.

Din, B.H., Anuar, A.R. and Usman, M., (2016). Does The Entrepreneurship Education Matters in Enhancing Entrepreneurial Skill Among Students in Malaysian Public 
Universities?. International Review of Management and Marketing, 6(7): 107111.

Dissanayake, D. M. and Semasinghe, D. M. (2016). Entrepreneurial Orientation and Growth: The Moderating Role of National Culture. Journal of Entrepreneurship and Organisation Management 5:168. doi:10.4172/ 2169-026X.1000168.

Driskill, G.W., (2018). Organizational culture in action: A cultural analysis workbook. Routledge.

Duru, I.U., Ehidiamhen, P.O. and Chijioke, A.N., (2018). Role of entrepreneurial orientation in the performance of small and medium enterprises: Evidence from federal capital territory,Abuja, Nigeria. Asian Journal of Economics, Business and Accounting, pp.1-21.

Emmanuel, Y., 2017. Influence of entrepreneurship education, technology and globalization on performance of SMEs in Nigeria. African journal of business management, 11(15): 367-374.

Fairlie, R.W., Miranda, J. and Zolas, N., (2019). Measuring job creation, growth, and survival among the universe of start-ups in the United States using a combined start-up panel dataset. ILR Review, 72(5): 1262-1277.

Farrington, S.M. and Matchaba-Hove, M.T.M., (2011). The Influence of Entrepreneurial Orientation on Small Business Success. The 23rd Annual Conference of the Southern African Institute for Management Scientists.

Fernández-Serrano, J., Berbegal, V., Velasco, F. and Expósito, A., (2018). Efficient entrepreneurial culture: a cross-country analysis of developed countries. International Entrepreneurship and Management Journal, 14(1): 105127.

Freiling, J. and LütkeSchelhowe, C., (2014). The impact of entrepreneurial orientation on the performance and speed of internationalization. Journal of Entrepreneurship, Management and Innovation, 10(4), p.169.

Frishammar, J. and Hörte, S. A. (2007). The Role of Market Orientation and Entrepreneurial Orientation for New Product Development Performance in Manufacturing Firms. Technology Analysis \& Strategic Management, 19(6): 765788.

Gibb, A. (2009). "The small business and entrepreneurship challenge to vocational education: Revolution or evolution?", paper presented at the OECD Conference 
on SMEs, Entrepreneurship and Innovation, Udine, Italy, 22-23 October 2009, OECD LEED Programme, Paris.

Gunawan, T., Jacob, J. and Duysters, G., (2016). Network ties and entrepreneurial orientation:Innovative performance of SMEs in a developing country. International Entrepreneurship and Management Journal, 12(2): 575599.

Hair, J. F., Ringle, C. M., and Sarstedt, M. (2011). PLS-SEM: Indeed a silver bullet. Journal of Marketing theory and Practice, 19(2), 139-152.

Hair, J. F., Risher, J. J., Sarstedt, M., and Ringle, C. M. (2019). When to use and how to report the results of PLS-SEM. European Business Review, 31(1), 2-24.

Hasche, N., and Linton, G. (2018). The value of failed relationships for the development of aMedtech start-up. Journal of Small Business \& Entrepreneurship, 30(1): 97-119.

Hofstede, G. (1980). Culture's consequences: International differences in work-related values. Beverly Hills, CA: Sage Publications.

Jackson, D. N. (1976). Jackson Personality Inventory Manual. Port Huron, MI: Research Psychologists Press.

Jalali, A., Jaafar, M. and Ramayah, T. (2014). "Entrepreneurial orientation and performance: the interaction effect of customer capital", World Journal of Entrepreneurship, Management and Sustainable Development, 10(1): 48-68.

Jones, P., Maas, G., Dobson, S., Newbery, R., Agyapong, D. and Matlay, H., (2018). Entrepreneurship in Africa, part 1: entrepreneurial dynamics in Africa. Journal of Small Business and Enterprise Development, 25(3): 346-348.

Kafetsios, K.G., (2019). Interdependent self-construal moderates relationships between positiveemotion and quality in social interactions: A case of person to culture fit. Frontiers inpsychology, 10.

Kececi, M., (2017). The Impact of Individualism and Collectivism on the Relationship Between Leadership Styles and Organizational Citizenship Behaviour. Research Journal of Business and Management, 4(4): 469-484.

Kerr, S.P., Kerr, W.R. and Xu, T., (2018). Personality traits of entrepreneurs: a review of recent literature. Foundations and Trends in Entrepreneurship, 14(3): 279356. 
Kerr, S.P., Kerr, W.R. and Dalton, M., (2019). Risk attitudes and personality traits of entrepreneurs and venture team members. Proceedings of the National Academy of Sciences, 116(36):17712-17716.

Knight, G. A. (2001). Entrepreneurship and strategy in the international SME. Journal of International Management, 7(3):155-171.

Kollmann, T., Christofor, J. and Kuckertz, A. (2007). Explaining individual entrepreneurial orientation: conceptualization of a cross-cultural research framework. International Journal of Entrepreneurship and Small Business, 4(3): 325-340.

Kraus, S., Rigtering, J. P. C., Hughes, M. \&Hosman, V. (2012). Entrepreneurial orientation and the business performance of SMEs: a quantitative study from the Netherlands. Review Management Science, 6:161-182.

Krueger, N. F. J., Reilly, M. D. and Carsrud, A. L. (2000). Competing models of entrepreneurial intention. Journal of Business Ventures, 15: 411-432.

Lechner, C. and Gudmundsson, S.V., 2014. Entrepreneurial orientation, firm strategy and small firm performance. International Small Business Journal, 32(1): 36-60.

Lee, Y., Howe, M. and Kreiser, P.M., (2019). Organisational culture and entrepreneurial orientation: An orthogonal perspective of individualism and collectivism. International Small Business Journal, 37(2): 125-152.

Lekhanya, L. M. (2016). 'Determinants of survival and growth of small and medium enterprises in rural KwaZulu - Natal'. (Unpublished PhD dissertation), University of Western Cape, Bellville, Cape Town.

Lesotho 2016 - FinMark Trust Report on Economy Outlook. P.16.

Lewis, R.D., 2006. When cultures collide: Leading across cultures (3d. ed.) Boston. MA: Nicholas Brealey Publishing: p. 559.

Lumpkin, G. T. and Dess, G. G., (1996). Clarifying the entrepreneurial orientation construct and linking it to performance. Academy of Management Review, 21(1): 135-172.

Markus, H., \&Kitayama, S. (1991). Culture and the self: Implications for cognition, emotion, and motivation. Psychological Review, 98, 224-2.

Ministry of Trade and Industry, Cooperatives and Marketing. (2008). The State of Small Enterprise in Lesotho, October. Accessed 25 th September 2019 from http://www.trade.gov.Is/documents/Lesotho State Small Enterprise Survey O ct 2008.pdf. 
Mancha, R.M. and Yoder, C.Y. (2015). Cultural antecedents of green behavioral intent: An environmental theory of planned behavior. Journal of Environmental Psychology, 43: 145 -154.

Martens, C. D. P., Lacerda, F. M., Belfort, A. C., and Freitas, H. M. R. D. (2016). Research on entrepreneurial orientation: current status and future agenda. International Journal of Entrepreneurial Behavior \& Research 22(4): 556-583.

Maslowsky, J., Jager, J. and Hemken, D., (2015). Estimating and interpreting latent variable interactions: A tutorial for applying the latent moderated structural equations method. International Journal of Behavioral Development, 39(1):.8796.

Miller, D. (2011) Miller (1983) revisited: A reflection on EO research and some suggestions for the future. Entrepreneurship: Theory \& Practice, 35(5): 873-894.

Nel, J., and Boshoff, C. (2019). Online customers' habit-inertia nexus as a conditional effect of mobile-service experience: A moderated-mediation and moderated serial-mediation investigation of mobile-service use resistance. Journal of Retailing and Consumer Services, 47, 282-292.

Neneh, B. N., Van Zyl, J. H., and Van Noordwyk, A. (2016). Gender Differences in Entrepreneurial Orientation and Performance: Evidence from South Africa. Conference paper submitted at the Southern African Institute for Management Scientists (SAIMS), 4-7 September 2016, Pretoria, South Africa.

Obi, J., Ibidunni, A.S., Tolulope, A., Olokundun, M.A., Amaihian, A.B., Borishade, T.T. and Fred, P., (2018). Contribution of small and medium enterprises to economic development: Evidence from a transiting economy. Data in brief, 18 : 835-839.

OECD, (2017). Enhancing the Contributions of SMEs in a Global and Digitalised Economy.

Ogunlusi, C.F., David, J.O., Atunbi, J.A. and Ajani, J.O., (2018). Employment Generation and Poverty Alleviation: The Effect of Entrepreneurship Development Programmes in Southwest Nigeria. World Journal of Entrepreneurial Development Studies, 2(3): 44-46.

Okangi, F.P., (2019). The impacts of entrepreneurial orientation on the profitability growth of construction firms in Tanzania. Journal of Global Entrepreneurship Research, 9(1), p.14. 
Oliveira Jr, A. B., Borini, F. M., Bernardes, R. C. \& De Oliveira, M. J. (2016).Impact of Entrepreneurlal Orientation on Strategic Alliances and the Role of Top Management. Revista de Administração de Empresas. 56(3): 1-15.

Ostapenko, N. (2015). National culture, institutions and economic growth: The way of influence on productivity of entrepreneurship. Journal of Entrepreneurship and public policy, 4(3), 331-351.

Prasad, S.H., Giridhar, K., Barkur, G. and Kiefer, N., (2018\}. Do Personal Traits, Creativity and Organizational Trust Influence the Innovative Skills of Technical Students an Evidence from a Private University?. International Journal of Entrepreneurship, 22(2): 1-10.

Păunescu, C., Popescu, M. and Duennweber, M., (2018). Factors Determining Desirability of Entrepreneurship in Romania. Sustainability, 10(11): 3893.

Rajapathirana, R.J. and Hui, Y., (2018). Relationship between innovation capability, innovation type, and firm performance. Journal of Innovation \& Knowledge, 3(1): 44-55.

Ray, J. (1979). A Quick Measure of Achievement Motivation-Validated in Australia and Reliable in Britain and South Africa. Australian Psychologist, 14(3): 337 344.

Rezaei, J. and Ortt, R., (2018). Entrepreneurial orientation and firm performance: the mediating role of functional performances. Management Research Review, 41(7): 878-900.

Schwarzer, R., and Jerusalem, M. (1995). Generalized Self-Efficacy scale. In J. Weinman, S. Wright, \& M. Johnston, Measures in health psychology: A user's portfolio. Causal and control beliefs (pp. 35-37). Windsor, UK: NFER-NELSON.

Shirokova, G., Tsukanova, T. and Morris, M.H., (2018). The moderating role of national culture in the relationship between university entrepreneurship offerings and student start-upactivity: an embeddedness perspective. Journal of Small Business Management, 56(1): 103-130.

Siu, W. S., and Lo, E. S. C. (2013). Cultural contingency in the cognitive model of entrepreneurial intention. Entrepreneurship Theory and Practice, 37(2), 147-173.

Staniewski, M. W. (2016). The contribution of business experience and knowledge to successful entrepreneurship. Journal of Business Research, 69 (11): 5147-5152. 
Tekola, H. and Gidey, Y., (2019). Contributions of Micro, Small and Medium Enterprises (MSMEs) to Income Generation, Employment and GDP: Case Study Ethiopia. Journal of Sustainable Development, 12(3).

UNDP (United Nations Development Programme), 2018. Human Development Report. New York.

Wach, K. (2015). Entrepreneurial Orientation and Business Internationalisation Process: The Theoretical Foundations of International Entrepreneurship. Entrepreneurial Business and Economics Review, 3(2): 9-24.

Wales, W. J., Gupta, V. K. and Mousa, F.T. (2013). Empirical research on entrepreneurial orientation: an assessment and suggestions for future research. International SmallBusiness Journal, 31(4): 357-383.

Wales, W., Gupta, V.K., Marino, L. and Shirokova, G., (2019). Entrepreneurial orientation:International, global and cross-cultural research. International Small Business Journal, 37(2): 95-104.

Wales, W., Wiklund, J., and McKelvie, A. (2015). What about new entry? Examining the theorized role of new entry in the entrepreneurial orientation-performance relationship.International Small Business Journal 33(4): 351-373.

Walker, G.J., Deng, J. and Dieser, R.B., (2005). Culture, self-construal, and leisure theory and practice. Journal of Leisure Research, 37(1): 77-99.

Wambugu, A.W., Gichira, R., Wanjau, K.N. and Mung'atu, J., (2015). The relationship between risk taking and performance of small and medium agro processing enterprises in Kenya. International Journal of Economics, Commerce and Management, 3(12):441-454.

Wang, R., (2012). Chinese culture and its potential influence on entrepreneurship. International Business Research, 5(10): 76.

World Babk Report, 2019 (retrieved 5 November, 2019). Available from https://www.worldbank.org/en/country/lesotho/overview.

Zampetakis, L. A., Kafetsios, K., Lerakis, M. and Moustakis, V., (2015). Investigating the role of self-construal in the formation of entrepreneurial intentions. Frontiers in psychology, 6,p.1085.

Zampetakis, L. A., Kafetsios, K., Lerakis, M., and Moustakis, V. S. (2017). An emotional experience of entrepreneurship: Self-construal, emotion regulation, and expressions to anticipatory emotions. Journal of Career Development, 44(2): 144-158. 
Zellweger, T. and Sieger, P. (2012). Entrepreneurial orientation in long-lived family firms. Small Business Economics, 38(1), 67-84.

Zhang, T., Xi, S., Jin, Y. and Wu, Y., (2017). Self-construal priming modulates selfevaluation under social threat. Frontiers in psychology, 8: 1759.

Zhang, H., Zhang, T., Cai, H., Li, Y., Wei Huang, W. and Xu, D., (2014). Proposing and validating a five-dimensional scale for measuring entrepreneurial orientation: An empirical study. Journal of Entrepreneurship in Emerging Economies, 6(2): 102-121.

Yoo, B., Donthu, N. and Lenartowicz, T. (2011). Measuring Hofstede's Five Dimensions of Cultural Values at the Individual Level: Development and Validation of CVSCALE. Journal of International Consumer Marketing, 23: 193210.

Yu, A., Lumpkin, G. T., Praveen Parboteeah, K., and Stambaugh, J. E. (2019). Autonomy and family business performance: The joint effect of environmental dynamism and national culture. International Small Business Journal, 37(2), 153185.

Table 1: Results of measurement model

\begin{tabular}{|l|l|l|l|l|}
\hline Constructs & Items/sub-scale & Outer loadings & AVE & CR \\
\hline \multirow{3}{*}{ Interdependent self-construal } & Coll1 & 0.939 & 0.894 & \multirow{2}{*}{0.944} \\
\cline { 1 - 3 } & Coll2 & 0.952 & & \\
\hline \multirow{3}{*}{ Independent self-construal } & Indiv1 & 0.941 & \multirow{2}{*}{0.789} & \multirow{2}{*}{0.918} \\
\cline { 2 - 3 } & Indiv2 & 0.920 & \\
\cline { 2 - 3 } & Indiv3 & 0.797 & \multirow{2}{*}{0.970} \\
\cline { 1 - 3 } Innovation & RT1 & 0.915 & \\
\cline { 2 - 3 } & RT2 & 0.944 & \\
\cline { 2 - 3 } & Innov1 & 0.928 & \\
\cline { 2 - 3 } & Innov2 & 0.940 & & \\
\cline { 2 - 3 } & Innov3 & 0.923 & & \\
\hline
\end{tabular}


Table 2: Results of discriminant validity

\begin{tabular}{lccc}
\hline & 1 & 2 & 3 \\
\hline 1. Entrepreneurial orientation & 0.930 & & \\
2. Independent self-construal & 0.588 & $\mathbf{0 . 8 8 8}$ & \\
3. Interdependent self-construal & 0.189 & 0.334 & $\mathbf{0 . 9 4 5}$ \\
\hline
\end{tabular}


Table 3: Means, Standard Deviations (SD) and Spearman's inter-correlation of variables

\begin{tabular}{|c|c|c|c|c|c|c|c|c|c|c|c|c|c|}
\hline Variable & $\begin{array}{l}\text { Mean } \\
\text { (SD) }\end{array}$ & 1 & 2 & 3 & 4 & 5 & 6 & 7 & 8 & 9 & 10 & 11 & 12 \\
\hline Gender & & - & & & & & & & & & & & \\
\hline Age & & 0.18 & - & & & & & & & & & & \\
\hline Education & & -0.09 & $-0.66^{* *}$ & - & & & & & & & & & \\
\hline Prior business experience & & $-0.28 *$ & 0.10 & 0.14 & - & & & & & & & & \\
\hline Independent & & $0.20^{+}$ & $-0.19^{+}$ & $0.27^{*}$ & -0.09 & $(0.93)$ & & & & & & & \\
\hline Interdependent & & $0.22^{*}$ & 0.05 & 0.04 & -0.17 & $0.43^{* *}$ & $(0.88)$ & & & & & & \\
\hline Uncertainty & & 0.14 & 0.12 & -0.03 & 0.00 & $0.46^{* *}$ & $0.52^{* *}$ & $(0.82)$ & & & & & \\
\hline Long-term planning & & -0.05 & $-0.27^{*}$ & $0.35^{* *}$ & -0.09 & $0.70^{* *}$ & 0.18 & $0.47^{* *}$ & $(0.91)$ & & & & \\
\hline Risk-taking & & -0.03 & $-0.26^{*}$ & $0.43^{* *}$ & 0.14 & $0.60 * *$ & $0.28 *$ & $0.25^{*}$ & $0.50^{* *}$ & $(0.96)$ & & & \\
\hline Innovativeness & & -0.05 & $-0.41 * *$ & $0.59 * *$ & 0.08 & $0.60 * *$ & $0.20^{+}$ & $0.20^{+}$ & $0.50^{* *}$ & $0.89 * *$ & $(0.95)$ & & \\
\hline Motivation & & -0.10 & $-0.36^{* *}$ & $0.54^{* *}$ & 0.15 & $0.43^{* *}$ & 0.13 & 0.15 & $0.52^{* *}$ & $0.83^{* *}$ & $0.85^{* *}$ & $(0.93)$ & \\
\hline Orientation & & -0.05 & $-0.39 * *$ & $0.57^{* *}$ & 0.12 & $0.62 * *$ & $0.22^{*}$ & $0.22^{*}$ & $0.52^{* *}$ & $0.93 * *$ & $0.99 * *$ & $0.83 * *$ & $(0.96)$ \\
\hline Enterprise growth & & -0.06 & $0.25^{*}$ & -0.06 & $0.33^{* *}$ & -0.08 & $-0.31 * *$ & -0.13 & 0.05 & 0.12 & 0.13 & $0.30 * *$ & 0.12 \\
\hline
\end{tabular}

Notes: ${ }^{+}$Significant at $0.10 ; *$ Significant at $0.05 ; * *$ Significant at 0.01 . Where relevant, Cronbach's alphas are shown in parentheses. 
Table 4: Results of regression analyses $(n=80)$

\begin{tabular}{lcc}
\hline Variable & Entrepreneurial Orientation & Enterprise Growth \\
\hline Gender & -0.03 & 0.10 \\
Age & -0.04 & $0.38^{* *}$ \\
Level of education & $0.41^{* *}$ & 0.05 \\
Prior business experience & $0.24^{* *}$ & $0.21^{*}$ \\
Independent self-construal & $0.36^{* *}$ & -0.16 \\
Interdependent self-construal & 0.10 & $-0.33^{* *}$ \\
Uncertainty avoidance & 0.04 & -0.17 \\
Long-term planning & 0.15 & 0.20 \\
Entrepreneurial orientation & 0.76 & $0.30^{* *}$ \\
$\boldsymbol{R}$ & 0.58 & 0.63 \\
$\boldsymbol{R}^{2}$ & 0.40 \\
${ }^{*} \beta$ significant at $0.05 ;{ }^{* *} \beta$ significant at 0.01. & \\
\hline
\end{tabular}

Table 5: Estimated path regression coefficients

\begin{tabular}{llccc}
\hline & & Estimate & $t$ & $\rho$ \\
\hline Interdependent self-construalEO $\longrightarrow$ & & -0.009 & 0.103 & n.sig \\
Independent self-construalEO $\longrightarrow$ & & 0.591 & 7.408 & sig \\
Interdependent self-construal $\longrightarrow$ Growth & -0.434 & 2.925 & sig \\
Independent self-construal $\longrightarrow$ & Growth & -0.112 & 0.891 & n.sig \\
EO & Growth & 0.264 & 2.629 & sig. \\
\hline
\end{tabular}


Figure 1: Structural model

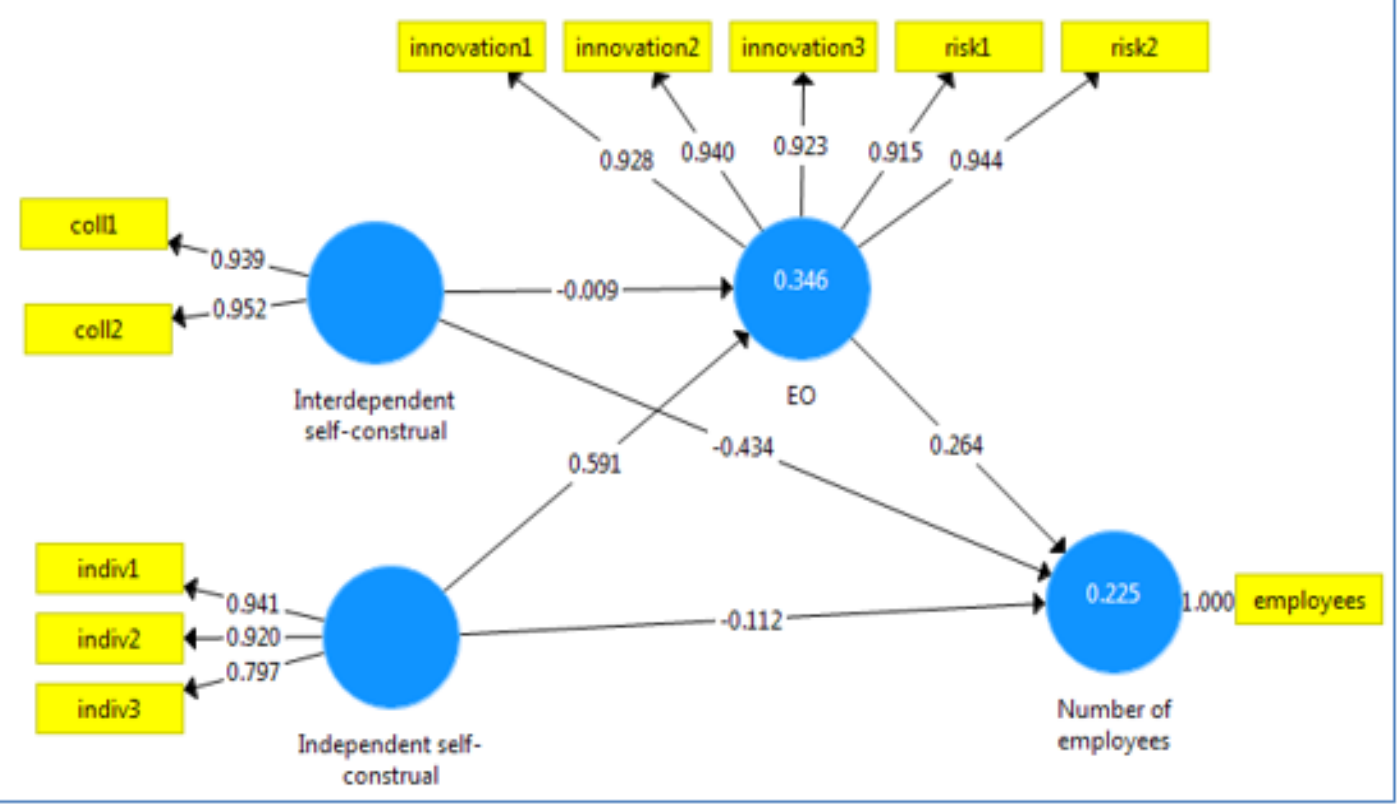




\section{Declarations}

\section{Ethics approval and consent to participate}

The National University of Lesotho has not formalised Research Ethics Committee. However, the ethics approval for the collection of data involving human participants is obtained from the Registrar office.

The ethics approval for the collection of data on "The Influence of Self-construal on Entrepreneurial Orientation and Growth of Micro-enterprises" among micro-business owners was given by the Registrar's Office of the National University of Lesotho

\section{Consent for publication}

Not applicable

\section{Availability of data and materials}

The datasets used and/or analysed during the current study are available from the corresponding author on reasonable request.

\section{Competing interests}

The authors declare that the Central University of Technology (CUT) Bloemfontein will be responsible for the payment of the publication fees as a way of promoting research as one of the authors is from CUT. Otherwise, the authors declare they have financial and non-financial competing interests.

\section{Funding}

The research study was privately funded by the authors.

\section{Authors' contributions}

The three authors participated equally in the write ups, data collection and analysis. 